\title{
Asistencia personal y discapacidad intelectual: un servicio para la inclusión social
}

\author{
Personal assistance and disability: a service for social inclusion
}

\begin{abstract}
Resumen
El servicio de asistencia personal es un servicio de ayuda personalizada para la vida independiente que se enmarca en el denominado "modelo de atención a la diversidad" y que reconoce la capacidad y el derecho de toda persona a disfrutar al máximo de su autonomía en el desarrollo de su proyecto de vida. En este trabajo se analiza una de las escasas experiencias en el territorio nacional de implantación del servicio para personas con discapacidad intelectual y/o enfermedad mental grave. Utilizando una metodología cualitativa (entrevistas semiestructuradas y grupos de discusión), la investigación aporta algunas reflexiones respecto a la identidad del servicio, el rol de los asistentes personales, la participación de las entidades colaboradoras y la valoración que de él hacen sus gestores y sus destinatarios directos e indirectos. El cierre del texto apunta algunos retos que se han de afrontar para la extensión y consolidación del servicio.
\end{abstract}

\section{Palabras clave}

Asistencia personal, discapacidad intelectual, enfermedad mental, vida independiente, España

\begin{abstract}
Personal assistance service is a personalized help service for independent living that is part of the "model to attend to diversity". It recognizes the capacity and the right of everyone to enjoy the maximum of his autonomy in development of his life project. This paper analyses one of the few experiences in Spain of implementation of the service for people with intellectual disability and/or severe mental illness. Using a qualitative methodology (semi-structured interviews and focus groups), the research provides some ideas about the identity of the service, the role of personal assistants, the participation of the voluntary sector and the assessment made by their managers and their target audience. The final part of the text marks some challenges that must be faced for the extension and consolidation of the service.
\end{abstract}

\section{Keywords}

Personal assistance services, intellectual disability, mental illness, independent living, Spain

\author{
Juan María Prieto Lobato \\ <juanmaria.prieto@uva.es> \\ Universidad de Valladolid. España

\section{Pablo de la Rosa Gimeno <pablo.rosa@uva.es>} \\ Universidad de Valladolid. España \\ José Luis Izquieta Etulain \\ <joseluis.izquieta@uva.es>
}

Universidad de Valladolid. España

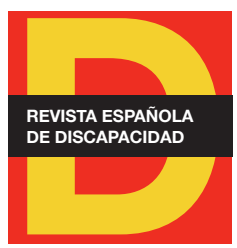

Para citar:

Prieto, J. M. et al. (2019): "Asistencia personal y discapacidad intelectual: un servicio para la inclusión social". Revista Española de Discapacidad, 7 (II): 7-27.

Doi: <https://doi.org/10.5569/23405104.07.02.01>

Fecha de recepción: 03-12-2018 Fecha de aceptación: 03-07-2019

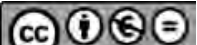


No es tan solo una cuestión de administrar la dosis justa, sino de llevar una vida placentera y que tenga sentido: con sistemas de apoyo, participando en la comunidad, sintiendo respeto por uno mismo y que los demás te respetan.

OLIVER SACKS (2016). En movimiento. Una vida. Anagrama: Madrid. p. 77.

\section{Introducción}

El servicio de asistencia personal (en adelante, SAP) es un servicio de ayuda personalizada para la vida independiente que reconoce la capacidad y el derecho de toda persona a disfrutar al máximo de su autonomía en el desarrollo de su proyecto de vida. El servicio supone un cambio radical respecto a la forma de entender y atender la discapacidad, puesto que ahora es el destinatario quien decide el tipo de apoyo, cuándo y cómo lo recibirá y quién se lo prestará, haciendo así efectivo el ejercicio de su autodeterminación.

La extensión de este modelo de apoyo a la discapacidad, amparada en un sólido ordenamiento jurídico internacional y nacional, encuentra su respaldo legal en España con la aprobación de la Ley 39/2006, de 14 de diciembre, de Promoción de la Autonomía Personal y Atención a las personas en situación de dependencia. Es a partir de este momento cuando algunas administraciones públicas locales y/o regionales -Guipúzcoa, Madrid, Barcelona- en colaboración con organizaciones del tercer sector de acción social y el denominado "Foro de Vida Independiente" -actualmente llamado "Foro de Vida Independiente y Divertad" (García Alonso, 2003)- comienzan a poner en marcha experiencias para la implantación del servicio para personas con discapacidad física (Rueda, 2013: 3). Son más escasas, sin embargo, las iniciativas dirigidas a personas con discapacidad intelectual, la mayoría gestionadas por asociaciones de personas con síndrome de Down de distintos puntos del país: Barcelona, Cádiz, Comunidad de Madrid, Huesca, Murcia y País Vasco (Villa Fernández, 2012: 109-117).

En esta poco explorada vía de extensión del SAP -su utilización por personas con discapacidad intelectual y/o enfermedad mental grave- se sitúa el proyecto piloto impulsado por la Gerencia de Servicios Sociales de la Junta de Castilla y León y el Comité Autonómico de Entidades de Representantes de Personas con Discapacidad en Castilla y León (CERMI-CyL) e implementado durante tres años (de 2014 a 2016) por seis entidades del tercer sector de acción social con implantación regional y/o provincial. El artículo que aquí presentamos recoge el estudio realizado a partir de este proyecto ${ }^{1}$ por un equipo de investigadores/as del departamento de Sociología y Trabajo Social de la Universidad de Valladolid².

El reducido número de investigaciones realizadas en España sobre esta temática (no así en el ámbito internacional; véase, por ejemplo, Askheim, 2003 o Axelsson et al., 2014, y el escaso conocimiento que se

\footnotetext{
1. Este artículo ha sido posible gracias a la confianza depositada en el equipo por la Gerencia de Servicios Sociales de la Junta de Castilla y León, financiadora del estudio, y a la colaboración, participación y disponibilidad de todas las personas que hicieron posible el trabajo investigador: personas beneficiarias, familiares, profesionales gestoras del SAP y gerentes de las entidades participantes en el proyecto piloto. Todos ellos son los auténticos protagonistas de la experiencia que ha sido objeto del estudio y son, por lo tanto, los autores en la sombra de este artículo. Sin ellos, sin su enorme generosidad en las entrevistas y en los grupos de discusión realizados, sin toda la información que nos han facilitado en primera persona, este trabajo no hubiera sido posible.

2. Los firmantes del artículo agradecen la contribución de Da Reyes Pérez Rico, Da Raquel Alario Bancells y D. Eduardo José Esteban Sancho.
} 
ha generado hasta el momento sobre el modo en que se asume, plantea y valora el SAP, justifican una aproximación sistemática y analítica. Tras un acercamiento a los modelos de atención a las personas con discapacidad y enfermedad mental, resaltando las diferencias y los cambios que introduce el SAP, se expone la metodología de investigación, así como los instrumentos y el proceso seguido en la recogida de la información. Los resultados más relevantes del proyecto ocupan la parte central del artículo, estructurados en torno a cuatro ejes: la identidad y las dimensiones del servicio, las organizaciones que lo prestan, el rol del asistente personal y la valoración que realizan las personas implicadas. El texto se cierra con una reflexión acerca del interés y de las potencialidades del SAP, así como de los retos que implica su implantación y gestión.

\section{Los modelos de atención a la discapacidad: el SAP como herramienta del modelo de la diversidad}

La discapacidad ha sido entendida de muy diversas maneras a lo largo de la historia, condicionando las prácticas cotidianas (respuestas de apoyo social incluidas), la identidad y la estratificación social de las personas con discapacidad (Vázquez Ferreira, 2008: 153). Aun a riesgo de simplificar mucho, se puede afirmar que la discapacidad ha sido entendida y atendida en base a dos modelos, que podemos denominar clínico y de apoyo familiar. Ambos se han desarrollado en ámbitos distintos -el de apoyo familiar, en el doméstico y relacional; el clínico, en el formal o institucional- y reflejan diferencias notables. No obstante, comparten una misma premisa: se basan en unas relaciones asimétricas en las que las personas que reciben ayuda se hallan supeditadas a las decisiones que toman quienes la prestan, siendo estas últimas las que deciden su modo de vida, la forma en que tienen que actuar y comportarse.

El modelo de apoyo familiar asume el cuidado de las personas con discapacidad y enfermedad mental como una obligación moral implícita en los deberes derivados de los lazos de parentesco. Asumiendo que ese cuidado debe realizarse en el propio hogar y, subsidiariamente, en una institución dedicada a su atención, se legitima una atención esencialmente paternalista donde las personas destinatarias viven una interminable minoría de edad que se convierte en un obstáculo insalvable para el disfrute de la autonomía y libertad que se reconoce a las personas adultas. Las relaciones que se establecen entre los prestadores y los receptores del servicio se fundan en el afecto: aquellos que ofrecen ayuda esperan reconocimiento, gratitud y aceptación de los que la reciben, mientras que estos, agradecidos, mantienen la esperanza de seguir recibiendo los apoyos que necesitan.

El modelo clínico, también conocido como médico-rehabilitador, destaca por girar en torno al poder del técnico encargado de las atenciones a las personas con discapacidad. Este poder se lo otorga el saber y las competencias que le son reconocidas-acreditadas en el marco de una organización de servicios especializados para personas con discapacidad. Los técnicos observan, valoran, establecen un diagnóstico de necesidades y proponen unos servicios estándar, de efectividad más o menos contrastada, y ajustados a las necesidades diagnosticadas. Ellos son los que asumen el protagonismo en una relación asimétrica donde prácticamente todo el poder está de su lado; a la persona destinataria le queda confiar en su destreza a la hora de interpretar sus intereses y en las bondades de los servicios prescritos. Se trata de un modelo eminentemente asistencialista que descuida el papel de las personas destinatarias de las atenciones, infantilizándoles y considerándoles incapaces de decidir qué ayudas quieren, cómo, cuándo y quién se las ha de prestar. 
Estos modelos se mantienen vigentes hasta los años sesenta del siglo pasado, momento en el que un grupo reducido de personas con discapacidad denuncia la exclusión que padecen, crea el Movimiento de Vida Independiente y plantea la puesta en marcha del denominado modelo de la diversidad. Este modelo, basado en los principios de autodeterminación, atención individualizada e inclusión comunitaria (Martínez, 2003: 135-156), contempla también la incorporación de un nuevo servicio de ayuda, el SAP, cuya pretensión es posibilitar a las personas con discapacidad una vida activa e independiente (de técnicos y familiares).

EI SAP consiste en un servicio desempeñado por un asistente personal profesional, que es contratado por la persona destinataria de sus servicios, convirtiéndose por ello en un cliente en el más amplio y estricto sentido de la palabra, con todo el poder que el rol de contratante/consumidor atribuye: elección y control del servicio, selección del prestador, determinación del tipo de servicio, elección del modo y momento de la prestación, negociación de precio...

Apoyándose en la premisa de que la discapacidad es una construcción social que tiene como consecuencia que la sociedad no considere adecuadamente a las personas con discapacidad (Palacios Rizzo, 2008: 471), plantea un cambio radical: las personas con discapacidad pasan de ser beneficiarias resignadas de decisiones que toman otras personas $u$ organizaciones a ser responsables de sus propias vidas. Estos rasgos hacen del SAP un servicio diferente a los que habitualmente se han dirigido a estas personas (ayuda a domicilio clásica, atención residencial, centro de día, apoyo familiar...).

El desarrollo y extensión de este servicio ha sido progresivo y desigual: aunque cuenta con un amplio refrendo internacional que parte del reconocimiento a "vivir de forma independiente y a ser incluido en la comunidad", como recoge la Convención de Naciones Unidas sobre los derechos de las personas con discapacidad (2006) (Asís y Barranco, 2010: 48). Tan solo unos pocos países europeos han aprobado leyes específicas sobre vida independiente, como es el caso de Suecia (1994) y Reino Unido (1997). Unos se han dotado de leyes generales de atención a la discapacidad, como Italia (2000), Noruega (2000) y España (2006), y otros aún no han desarrollado normas de ningún tipo (European Network of Independent Living, 2014).

En España, la aprobación de la Ley 39/2006, de 14 de diciembre, de Promoción de la Autonomía Personal y Atención a las personas en situación de dependencia constituyó un avance importante para la ciudadanía, al considerar el fomento de la autonomía personal y la atención a las situaciones de dependencia un derecho subjetivo. El artículo 19 de esta Ley establece "la prestación económica de asistencia personal para la promoción de la autonomía de las personas con dependencia, señalando como su objetivo contribuir a la contratación de una asistencia personal, durante un número de horas, que facilite a la persona beneficiaria el acceso a la educación y al trabajo, así como una vida más autónoma en el ejercicio de las actividades básicas de la vida diaria". Esta formulación permite a algunos autores afirmar que la ley española materializa esta prestación de una forma restrictiva (láñez-Domínguez et al., 2018: 82).

Un análisis del marco jurídico regulador del SAP en las diferentes comunidades autónomas que conforman el Estado español revela algunas diferencias en su tratamiento sobre la base de unos parámetros comunes que la propia Ley 39/2006 estableció. Las discrepancias en la normativa autonómica se refieren, fundamentalmente, a los requisitos de acceso, la capacidad jurídica -necesaria o no- para poder solicitar la prestación, así como la definición y descripción de las actividades del SAP que facilitan el acceso a la educación y al trabajo y las que posibilitan mayor autonomía en las actividades básicas de la vida diaria. Respecto a la 
prestación del servicio, no existe todavía un desarrollo en la cualificación profesional homologada para las personas empleadas en este servicio.

\section{Metodología}

El objeto y los objetivos de la investigación fueron establecidos en el encargo recibido de la entidad pública responsable de los servicios sociales en la comunidad autónoma de Castilla y León: establecer las fortalezas, debilidades y potencialidades de un proyecto piloto sobre el SAP para personas con discapacidad intelectual y personas con enfermedad mental grave. Aunque era responsabilidad exclusiva del equipo investigador diseñar una estrategia metodológica adecuada a ese objeto y objetivos, se consensuó con la autoridad contratante la utilización de una estrategia cualitativa dado el interés que implicaba analizar cómo las distintas personas implicadas (stakeholders) perciben y valoran el objeto de estudio, sus conocimientos e interpretaciones.

De manera conjunta se consideró interesante realizar una aproximación comprensiva del SAP desde el punto de vista de sus protagonistas, desde el convencimiento de que no es posible comprender la realidad social en toda su extensión sin atender el discurso de sus agentes, sin dar primacía a los aspectos subjetivos desde el propio mundo de los actores (Ruiz Olabuénaga, 2012: 44).

Una vez elegida la metodología, se estableció un cuidado proceso de recogida sistemática de información que contempló tres fases claramente diferenciables y el uso, en cada una de ellas, de distintas técnicas e instrumentos: 1) Aproximación teórica-conceptual al SAP, 2) Acercamiento prospectivo a la naturaleza de este servicio mediante la realización de dos entrevistas a expertos en la materia, y 3) Trabajo de campo propiamente dicho.

Tabla 1. Ficha técnica de la investigación
\begin{tabular}{|l|l|}
\hline Objeto & $\begin{array}{l}\text { SAP para personas con discapacidad intelectual y personas con enfermedad mental grave por } 6 \\
\text { entidades del tercer sector de acción social en cinco provincias de Castilla y León: Ávila, León, } \\
\text { Salamanca, Valladolid y Zamora. }\end{array}$ \\
\hline Objetivo & $\begin{array}{l}\text { Determinar las fortalezas, debilidades y potencialidades del servicio desde la perspectiva de las } \\
\text { diferentes personas implicadas. }\end{array}$ \\
\hline Metodología & Cualitativa. \\
\hline Herramientas & $\begin{array}{l}\text { Estudio documental (53 referencias bibliográficas y 13 legales). } \\
\text { Eormularios auto-cumplimentados (6). } \\
\text { Grupos de discusión (4). }\end{array}$ \\
\hline Trabajo de campo & 11 meses: de mayo de 2015 a abril de 2016. \\
\hline $\begin{array}{l}\text { Tratamiento de } \\
\text { datos }\end{array}$ & Atlas.Ti. \\
\hline
\end{tabular}

Fuente: elaboración propia. 
Conocidas las entidades participantes en el proyecto piloto, el equipo de investigación entró en contacto con ellas y recogió, a través de un formulario auto cumplimentado vía web, la información más relevante sobre la participación e implicación de esas entidades en el SAP.

A partir de esta información se planteó el guion de las 27 entrevistas que se realizaron a distintas personas implicadas: beneficiarios, familiares, coordinadores, gerentes y asistentes personales. La entrevista, en la modalidad semiestructurada, se planteaba de forma diferente según fuera la tipología del entrevistado. Todas las entrevistas comenzaban con una presentación: motivos, contenido, finalidad, confidencialidad, permiso para la grabación... y se cerraban con preguntas relativas a la valoración general del servicio. De manera específica se trataban contenidos asociados al perfil de la persona entrevistada. En el caso de los beneficiarios, la entrevista se centraba en la experiencia de contar con un asistente personal, la relación con él o ella y cómo había impactado en su vida cotidiana. Las entrevistas a familiares ponían su foco en el impacto percibido en la persona atendida y su entorno familiar y en asuntos referidos a la gestión-acceso al SAP. En la entrevista a los gestores y coordinadores del SAP se preguntaba por muy diversas cuestiones, desde los perfiles de las personas atendidas y de los propios asistentes personales, hasta las relaciones entre asistente personal y la persona beneficiaria del servicio, pasando por cuestiones como la coordinación, regulación, apoyo público o impacto en la vida de las personas beneficiarias. Las entrevistas a los asistentes personales pivotaban en torno a su experiencia profesional con personas con discapacidad intelectual y enfermedad mental grave, su opinión sobre la figura del asistente personal (contenido, reconocimiento, formación, regulación...) y la coordinación con otros servicios o figuras profesionales.

Analizadas las informaciones resultantes de la primera parte del estudio de campo, se pudieron seleccionar los asuntos más relevantes y críticos en torno al SAP y se plantearon cuatro grupos de discusión conformados por los principales actores comprometidos en el diseño, gestión, prestación y recepción del servicio.

El valor de los grupos de discusión reside en que trasciende el discurso individual y se van conformando, a través de la interinfluencia de los participantes, las ideas más o menos compartidas, las representaciones "sociales" de los temas tratados, tal y como ocurre en la vida cotidiana: nuestras percepciones e ideas se van conformando en continua interacción con nuestro entorno. La riqueza y espontaneidad de los discursos que se suceden en estos grupos hacen que la información que aportan sea muy relevante y significativa (Vallés, 2002; Alonso, 2003). En él se comparten y discuten ideas, imágenes, opiniones, valoraciones particulares que han de ser consideradas a la luz de una carga de elementos culturales, ideológicos e idiosincráticos que caracterizan al grupo y que moldean la especificidad del asunto que los investigadores tratan de abordar (Suárez Ortega, 2005).

En cada reunión, y en función de la dinámica establecida entre las personas participantes, el moderador del grupo fue dirigiendo la conversación hacia los temas contenidos en el guion establecido. La presencia e intensidad en el tratamiento de cada uno de los temas ha dependido siempre de la composición de cada grupo y de la decisión de sus participantes. No obstante, el desarrollo del guion se completó de manera satisfactoria en todas las reuniones con los siguientes apartados: a) consideración de la diversidad funcional intelectual y la enfermedad mental en nuestra sociedad, así como la evolución en la asistencia a ambos colectivos; b) elementos clave del SAP; c) la gestión y organización del SAP; d) los asistentes personales: perfil, formación para el ejercicio profesional, condiciones laborales, etc.; e) los agentes implicados: tercer sector de acción social, administraciones públicas, empresas, etc. y la contratación directa, y f) la valoración general del SAP. 


\begin{tabular}{l}
\hline Tabla 2. Perfil y número de personas entrevistadas y participantes en los grupos de discusión \\
\begin{tabular}{|l|c|c|}
\hline Perfil & $\begin{array}{c}\text { Personas } \\
\text { entrevistadas: }\end{array}$ & $\begin{array}{c}\text { Participantes } \\
\text { en grupos de } \\
\text { discusión: }\end{array}$ \\
\hline Personas beneficiarias & 4 & 3 \\
\hline Familiares de personas beneficiarias & 5 & 1 \\
\hline Coordinadores/as & 6 & 4 \\
\hline Gerentes de entidades prestadoras del servicio & 6 & 5 \\
\hline Asistentes personales & 6 & 5 \\
\hline Total & $\mathbf{2 7}$ & $\mathbf{1 8}$ \\
\hline
\end{tabular}
\end{tabular}

Fuente: elaboración propia.

Las entrevistas y los grupos de discusión se realizaron en diferentes ciudades y pueblos de la región, en orden a garantizar entornos amigables, facilitadores del debate y la reflexión. Con el consentimiento de todas las personas participantes, las entrevistas y las reuniones grupales fueron grabadas y posteriormente transcritas, representando un material de altísima calidad que fue ordenado, codificado y analizado mediante el software Atlas.ti. Tras un primer análisis temático (Boyatsis, 1998), se realizó un análisis sociológico en el que se reconstruyeron, analizaron e interpretaron las dinámicas discursivas a la luz de las diferentes aportaciones grupales.

Siguiendo las recomendaciones de Giménez Bertomeu (2014), en el desarrollo de esta investigación no se han realizado experimentos con personas, se han evitado intrusiones innecesarias en su vida, se ha evitado exponerlas a riesgos, estrés o malestares innecesarios y se han adoptado las medidas necesarias para asegurar el tratamiento confidencial de sus datos personales (con este objetivo, se han cambiado los nombres recogidos en los fragmentos de entrevistas y grupos de discusión recogidos en el texto). Los autores no reconocen ningún conflicto de interés en el diseño y ejecución del estudio, ni en la presentación y divulgación de sus resultados.

\section{Identidad y alcance del servicio de asistencia personal}

Como ya reflejamos en los apartados anteriores, la atención a la discapacidad ha vivido un avance significativo en las dos últimas décadas con la extensión e implantación de modelos superadores de los esquemas clásicos de atención clínica y familiar. Este proceso ha tenido, también, su reflejo social en la terminología que se emplea tanto en el discurso político-institucional como técnico. Aunque con múltiples detractores tanto en la esfera académica -Moscoso (2006), por ejemplo, conceptualiza la discapacidad como categoría política, paradigma de las reivindicaciones sociales postmodernas-, como en el movimiento asociativo -el COCARMI (2016) defiende el concepto de discapacidad por ser socialmente reconocido y contar con el amparo de Naciones Unidas-, el uso del término diversidad funcional se entiende como una valiosa herramienta que 
denota mayor neutralidad valorativa que otros términos (dependencia, discapacidad, minusvalía...) y supone un avance en el proceso de des-estigmatización y ruptura de etiquetas a las que han estado sometidas tradicionalmente las personas con discapacidad (Romañach y Lobato, 2005). En palabras de sus protagonistas, mientras que el viejo término presenta ciertas connotaciones negativas hacia la persona y genera cierta comparación peyorativa, el nuevo rompe con visiones limitadoras y abre camino a nuevas perspectivas para entender y comprender a las personas:

“El lenguaje cambia actitudes. Suena todavía un poco snob: 'y ahora éstos se han inventado una palabra nueva, ¿no?'. Empezamos con retraso mental, luego discapacidad intelectual, (...) No es lo mismo, eso va cambiando un poco lo que tenemos dentro (...). Cambia completamente, o sea, es que nos equipara, rompemos con esa barrera que teníamos antes en "ellos y nosotros". Es que somos todos, todos somos diversos" (GD1. Coordinadoras del SAP, p. 5).

Los viejos paradigmas de la prescindencia y la rehabilitación dieron paso a un modelo social basado en el reconocimiento de los derechos humanos (Brisenden, 1986; Hughes y Paterson, 1997; Oliver, 1983) y este, al modelo de la diversidad: la discapacidad es un fenómeno social y el que discapacita, en definitiva, es el entorno. Ya no se concibe a las personas con discapacidad como problemas sino que lo que existe son prácticas de discapacitación (láñez-Domínguez y Lobato Galindo, 2006; López-Pérez y Ruiz Seisdedos, 2013; Palacios y Romañach, 2006; Rodríguez Picavea-Matilla, 2010). El origen de las dificultades está fuera de la persona - en la sociedad - y, en consecuencia, su participación plena en la totalidad de las áreas de la vida en comunidad, el ejercicio legítimo de sus derechos, requiere la realización de todas las modificaciones y adaptaciones necesarias en su entorno (Palacios y Bariffi, 2007: 22-23). Este modelo sitúa a la persona en el centro de todas las decisiones que le afectan:

"Para mí, el mayor cambio ha sido la consideración de la discapacidad desde el concepto de ciudadanía, al mismo nivel que los derechos de cualquier otra persona. Y luego empezar a abordar la intervención no solo desde la perspectiva del experto, sino desde las necesidades del usuario como ciudadano que reclama unos derechos igual que cualquiera de nosotros" (GD2, Gerentes de entidades prestadoras del SAP, p. 2).

En el marco de este modelo de la diversidad, el SAP se caracteriza, sobre todo, por ser un servicio ad hoc, es decir, un servicio adaptado y ajustado a la persona beneficiaria, donde él es el experto y decide con quién, cómo y cuándo quiere que sean satisfechas sus necesidades. Pero más allá de esta sencilla definición... ¿cuáles son, a la luz de esta caracterización, los rasgos definitorios del servicio?, ¿qué dimensiones le singularizan frente a otros servicios de apoyo?, ¿estos rasgos y dimensiones tienen una naturaleza estrictamente individual, derivada de su condición "personal"? y, en el caso de no ser así, ¿en qué se concreta su naturaleza supraindividual?

Posiblemente dos de los rasgos más significativos e identificadores del servicio son su flexibilidad -se adapta a las necesidades, potencialidades y características de la persona beneficiaria, quien se convierte en la planificadora de las actividades y tareas que conforman el servicio- y su carácter personalizado, que responde a las carencias y demandas más importantes de las personas en función de su ciclo vital y proyecto de vida: inclusión comunitaria, acompañamiento fuera del hogar, apoyo escolar, apoyo en las actividades básicas de la vida diaria, etc.

"Mucha flexibilidad, aquí no valen para nada dogmas, protocolos muy estrictos... hay que amoldarse al perfil de cada persona: no es lo mismo una persona de 60 años que otra de 25 o 30, necesitas acompañarle o ir a correr 
un día a ver si le pica el gusanillo porque no quiere ir solo; y en otros es echar una partida de cartas y tiene que ser en casa. Hay que ver qué gustos tiene, de dónde puedes tirar, cómo les puedes estimular" (Entr. 0503. Asistente personal, p. 4-5).

Aunque pareciera redundante decir que la asistencia personal es personalizada, en realidad no lo es: el primer adjetivo alude al carácter del asistente; el segundo, a la adaptación específica de la asistencia (láñez-Domínguez y Lobato Galindo, 2006). Personalización y flexibilidad permiten decir que, del modelo de atención centrado en la persona, muy presente en las fórmulas contemporáneas de intervención social, se pasa ahora al modelo de atención planificado por la persona; ni los adjetivos ni las preposiciones son aquí baladíes:

"Lo que más me gusta de este servicio es que al final hacen lo que les da la gana como hacemos cualquiera. ¿Necesitan un apoyo? Sí, pero... ¿y ya está? Esto es a la carta, la persona desde el minuto uno es quien elige” (GD4. Asistentes personales, p. 5).

EI SAP implica, asimismo, atender de forma diferente a la persona en diferentes espacios y contextos. Es por esto por lo que, junto a la flexibilidad y la personalización del servicio, otro de los elementos identitarios del SAP es la contextualización del proceso de ayuda. A diferencia de otros modelos y/o servicios, el SAP no desvincula a la persona de su entorno, no la fragmenta en base a las atenciones que recibe ni la separa de su ambiente originario; por el contrario, hace de su participación en la comunidad un elemento central de su concepción y de su implementación, superando una exclusiva dimensión individual de la ayuda, en beneficio de una dimensión relacional guiada por su receptor:

"A mí me parece que es una prestación, que es una medida pensada para prolongar la estancia, la autonomía y la independencia de las personas en base a sus contextos" (GD2. Gerentes de entidades prestadoras del SAP, p. 3).

Algunas palabras-talismán de la intervención social se cargan ahora de valor: integral, integrada, globalizadora, participativa...; también adquieren sentido algunos rasgos clásicos en los postulados teleológicos y éticos de la acción social: mejora en la calidad de vida, definición de un proyecto de vida, adaptación a las características del ciclo vital, inclusión e integración social...

"Lo que ha hecho es proporcionar el acceso a recursos comunitarios ordinarios, es decir, cosas que los chicos querían hacer, pero no podían hacer porque solos no podían ir a ningún sitio. Lo que ha posibilitado es que esa persona entre en esas actividades y ayude a suplir un poco la falta de capacidad y la toma de decisiones de estos chicos, el acceso a cosas que ellos realmente querían hacer y no podían hacer" (GD1. Coordinadoras del SAP, p. 7).

EI SAP responde, de esta forma, tanto a las demandas de naturaleza y orden individual de la persona beneficiaria como aquellas otras que le conectan con su red social primaria y secundaria, hasta el punto que también esta pasa a ser beneficiaria indirecta del servicio.

La intervención del asistente personal tiene en cuenta las necesidades de las personas destinatarias de su ayuda y se marca como objetivo conseguir la mejora de su calidad de vida, lo que ineludiblemente pasa por garantizar la integración social y la participación en su comunidad de referencia. Es lo que podríamos identificar como la cuarta seña de identidad del SAP: su dimensión comunitaria en dos sentidos complementarios. Por un lado, la conexión de las personas con discapacidad intelectual con nodos personales e 
institucionales, el refuerzo de los vínculos y lazos que enriquecen su experiencia vital (Barrón, 1996: 49-50), la participación en actividades colectivas -fiestas, excursiones, actividades recreativas- (Axelsson et al., 2014), el acceso y disfrute de bienes y servicios sociales, educativos, de empleo, deportivos, culturales... son, sin duda, beneficios directos que atañen a la persona en un plano individual y social. Pero, por otro lado, los beneficios son extensibles a ese mismo entramado en la medida en que este se convierte, también, en objeto indirecto de intervención por parte del propio servicio. La preparación del entorno para la inclusión social se traduce en tareas tales como visibilizar las barreras socioculturales respecto a la discapacidad y/o la enfermedad mental grave, sensibilizar al resto de la comunidad sobre sus derechos, potenciar los resortes institucionales con capacidad para generar contextos exclusivos, etc.:

"La parte de la participación comunitaria ha sido un reto y está especialmente ligada a la del asistente personal. Si tú organizas tus centros como entorno cerrado no hace falta un asistente personal, pero en el momento en que planteas si esas personas tienen un proyecto de vida, un sueño y un objetivo se ha de trabajar las posibilidades que ofrece su entorno" (Entr. 0101. Gerente de entidad prestadora del SAP, p. 9).

\section{Las entidades que gestionan y prestan el servicio}

Como es bien conocido, las fórmulas establecidas de acceso al SAP por el Sistema para la Autonomía y Atención a la Dependencia son dos: el pago directo y el pago indirecto vinculado al servicio. El primero implica que la administración entrega directamente la cuantía económica a la persona con discapacidad o a su tutor legal para que este gestione el servicio de forma individual; el segundo supone que la administración competente, previo consentimiento de la persona beneficiaria, transfiere la cuantía de la prestación económica a la entidad que la persona elija para recibir la asistencia (Ortega Alonso, 2015: 26).

Tanto en el caso del pago directo (si así lo considera la persona perceptora de la ayuda), como en el caso del pago indirecto vinculado, las cooperativas de personas beneficiarias (también llamadas oficinas de vida independiente - OVI), las empresas y/o las entidades cogestoras del tercer sector de acción social juegan un papel decisivo en la prestación del SAP. Este último fue, como apuntamos en apartados precedentes, el caso del proyecto piloto analizado en este estudio: seis entidades sociales con amplia trayectoria en la atención a personas con discapacidad intelectual y/o a la enfermedad mental grave en Castilla y León asumieron la iniciativa de poner en marcha el servicio para sus beneficiarios. Este hecho permite reflexionar sobre aspectos diversos: ¿qué potencialidades ofrecen de acuerdo a la naturaleza comunitaria del servicio?, ¿en qué se concreta la ayuda de estas entidades como mediadoras entre personas beneficiarias y asistentes personales?, ¿qué valor perciben los beneficiarios en estas entidades para que dejen en sus manos la gestión de un asunto tan relevante para su bienestar? Se comenzará por este último interrogante.

El valor de este tipo de entidades se entiende, sobre todo, en términos de confianza para la persona beneficiaria (Power, 2013) -que deja en sus manos el proceso de selección de los asistentes personales y los múltiples e intrincados trámites burocráticos que implica su contratación (Planas García de Dios, 2013: 48)- y en términos de saber hacer, especializado y adaptado para los profesionales: 


\begin{abstract}
"Nos encargamos de la búsqueda y selección de personas, algo que probablemente una familia no pueda hacer. Por otro, diseñamos e impartimos la formación que esa persona debe tener" (Entr. 0601. Gerente de entidad prestadora del SAP, p. 10).
\end{abstract}

La dimensión comunitaria del servicio implica una estrecha coordinación de las entidades con diferentes agentes informales y formales del entorno convirtiéndose en un eje vertebrador del SAP, ya sean personas: familiares, amigos, vecinos, auxiliares de ayuda a domicilio, personal de teleasistencia, voluntariado, médicos, auxiliares técnicos educativos, trabajadores sociales, profesionales de los equipos de promoción de la autonomía personal... u organizaciones: colegios, cines, bibliotecas, ludotecas, CEAS, centros de salud mental, asociaciones de discapacidad, etc. Esta coordinación interinstitucional, entre personas, servicios y/o entre profesionales, se realiza en función del proyecto personal o de la etapa del ciclo vital en la que se encuentra la persona beneficiaria, atendiendo a sus capacidades, necesidades, demandas, aficiones, intereses, etc. La confluencia de diversas fuentes de apoyo formal e informal alienta sinergias muy significativas que difícilmente pueden ser generadas por servicios de otra índole.

Cuando una misma entidad presta el servicio a personas con perfiles diferentes, como hemos comprobado en esta investigación, la complejidad de la coordinación se acrecienta porque cada una de ellas exige conexiones con dispositivos diferentes, multiplicándose, también, las dificultades inherentes al trabajo en red (González Gago, 2010; Ubieto Pardo, 2009). En ello influye, por un lado, el desconocimiento acerca de las funciones y los roles del asistente personal, lo que provoca ciertas reticencias a la hora de introducir esta figura en algunos ámbitos cotidianos de la vida de las personas y exige un plus de sensibilización e información. Por otro lado, puede aparecer cierta fricción con otros servicios de atención personal, sobre todo con la ayuda a domicilio que, si bien en su definición estricta queda circunscrita a los confines domésticos, en su concepción integral adquiere un carácter preventivo, educativo y rehabilitador de primer orden (Rodríguez Castedo, 2004: 357-359):

\footnotetext{
"No todos los colegios están muy abiertos a que el asistente personal entre en su centro. Es una cosa nueva, siempre ante lo nuevo tenemos cierta reticencia" (Entr. 0401. Gerente de entidad prestadora del SAP, p. 6).

"La coordinación con el servicio de ayuda a domicilio es complicada porque la persona del SAD nos ve como una amenaza a su trabajo" (Entr. 0102. Coordinadora del SAP, p. 11).
}

Por último, la selección y reclutamiento de las personas que ejercen como asistentes personales es, también, otro asunto clave en el SAP y, sin duda, una de las grandes potencialidades que las entidades colaboradoras utilizan para justificar su papel mediador entre la persona beneficiaria y la prestadora del servicio. La vía de la contratación directa no resuelve bien algunos problemas de adaptación, sintonía y conexión entre asistentes y asistidos ni solventa con agilidad su sustitución en casos de enfermedad o vacaciones. También es posible que la persona que se contrate por esta vía no sea la más idónea para las peculiares tareas que exige la atención de una persona con enfermedad mental grave o discapacidad intelectual. Frente a estas dificultades, las entidades no lucrativas garantizan la profesionalidad y la idoneidad del personal técnico porque conocen a las personas beneficiarias, les ofrecen la ayuda que se adapta mejor a sus limitaciones y potencialidades, se preocupan de que los asistentes personales estén cualificados, hacen un seguimiento de su desempeño y articulan procesos de evaluación y control del servicio:

"Si hay un profesional detrás de una asistencia personal te da cierta garantía que el asistente personal que estás enviando va a encajar, le voy a poder formar, le voy a poder seleccionar dentro de los que yo considero que tienen mejores actitudes, vamos a poder cribar" (GD2. Gerentes de entidades prestadoras del SAP, p. 7). 


\section{Los asistentes personales: tareas y competencias}

Begoña Román (2010: 16) plantea que un servicio es siempre una relación interpersonal en la que alguien hace algo para otro; el servicio es algo diferente que el mero producto porque la calidad de aquel dependerá de la relación interpersonal. Este es, precisamente, un elemento clave del SAP en tanto que el vínculo que el asistente personal establece con la persona beneficiaria determina, en buena medida, las posibilidades de que la persona haga efectivo su proyecto de vida independiente. ¿Qué tareas realizan los asistentes personales?, ¿quién y cómo se deciden?, ¿qué cualidades, habilidades y destrezas hacen de una persona un asistente personal idóneo?, ¿cómo se forma y prepara para prestar ayuda de la mejor forma posible? Todas son preguntas cuya respuesta, por su transcendencia en la concreción del servicio, merecen ser objeto de atención.

Como parece bastante comprensible, las tareas que realizan los asistentes personales se caracterizan por tres rasgos fundamentales: de un lado, son sumamente variadas, desde la conducción hasta la comunicación, acompañamiento, tareas del hogar o personales (Ortega Alonso, 2015: 21-22); de otro, están adaptadas a las características de las personas destinatarias de su intervención, su edad, sus capacidades y, en consecuencia, a los objetivos que se establecen por los técnicos en los proyectos individualizados en el marco del SAP; y, en tercer lugar, se definen mediante un complejo proceso de negociación multilateral.

El conjunto heterogéneo de estas actividades podría clasificarse, en términos de preparación y dedicación, en dos grandes grupos: de baja y de alta exigencia. Entre las primeras se encuentran, por ejemplo, el apoyo y orientación en la movilidad y desplazamiento (uso del transporte público), la ayuda en actividades de la vida cotidiana (higiene personal, de la casa, vestido, cocina, etc.), el acompañamiento (a consultas médicas, actividades comunitarias, actividades deportivas, actividades extraescolares, etc.), el apoyo en la gestión económica (distribución de recursos económicos, planificación de gastos, etc.) y otras de naturaleza similar. Entre las segundas, nos referimos a actividades como apoyo emocional, mejora de habilidades sociales, procesos de modificación de conducta, trabajo en déficits de comunicación, gestión emocional, apoyo en la lecto-escritura, uso de tecnologías de la información y la comunicación, etc.

\footnotetext{
"Víctor hace casi todo: le ayudo a preparar la ropa para el día siguiente, si lo necesita le presto apoyo verbal para ir duchándose, reviso si se ha abrochado un botón, cómo se ha vestido... De ahí nos vamos a la universidad; este mes hemos trabajado con apoyo verbal el camino a la facultad o si necesita ayuda cuando lleva muchos líquidos en la bandeja." (Entr. 0103. Asistente personal, p. 2).

"Trabajamos mucho las emociones, gestionar las emociones cuando está fuera, porque Violeta está seis o siete horas en el colegio, por lo que debe de autogestionar sus emociones, entender las situaciones sociales que pasan alli" (Entr. 0403. Asistente personal, p. 3).
}

A diferencia de la discapacidad física -en la que la persona beneficiaria define directamente y de manera autónoma las tareas que ha de hacer su asistente personal (Planas García de Dios, 2013: 35)-, en el caso de las personas con discapacidad intelectual y/o enfermedad mental grave con la capacidad de obrar modificada, la identificación de estas tareas resulta de la confluencia de las demandas de las propias personas beneficiarias y/o de sus familiares o representantes legales y de la valoración del equipo técnico que realiza el seguimiento de cada caso. A efectos de considerar el peso de cada una de estas perspectivas en los pro- 
yectos individualizados de vida independiente se pueden observar dos planos diferenciados: de un lado, el diseño de la intervención a realizar en cada caso y, de otro, la ejecución de actividades y tareas concretas. Como es obvio, en el primer plano cobra especial importancia la valoración del equipo técnico; el segundo es el resultante de un complejo proceso de negociación entre persona beneficiaria, representantes legales y asistente personal. Este proceso para la toma de decisiones se justifica en el marco de un proceso de capacitación y empoderamiento del beneficiario/a:

"Es una visión un poco diferente de la típica idea que se tiene de un cuidador porque es al revés -que es lo que a mí me gusta de ser asistente personal-: la persona con discapacidad al fin y al cabo es como tu jefe, es la que te demanda y te pide y tú eres sus ojos, en este caso el que le acompañas” (Entr. 0203. Asistente personal, p. 3).

La heterogeneidad de las tareas encargadas a los asistentes personales y la complejidad del proceso de toma de decisiones en su definición exige, como es comprensible, que estos tengan ciertas cualidades y competencias adquiridas en un proceso adecuado de preparación o formación. Personas beneficiarias y sus familiares, asistentes personales, coordinadoras de los servicios y gerentes de las entidades, todos de forma unánime, no dejan lugar a dudas: el ejercicio profesional exige la puesta en práctica de competencias muy diversas que podríamos agrupar en torno a cinco grupos: habilidades sociales (empatía, asertividad, escucha activa...); actitudes (flexibilidad, adaptabilidad a la persona y sus capacidades...); competencias personales (paciencia, constancia, optimismo, que inspire confianza...); competencias profesionales (distancia emocional, destreza técnica, clarificación del rol profesional, trabajo en equipo), y competencias axiológicas (responsabilidad, respeto, protagonismo de la persona beneficiaria...). Manifestaciones de las protagonistas de esta relación personal/profesional ilustran con claridad algunas de estas apreciaciones:

"Yo destacaría las habilidades para la resolución de problemas, esa capacidad, esa empatía para ponerte en el lugar de la persona y comprenderla, habilidades sobre todo para trabajar en grupo" (Entr. 0402. Coordinadora del SAP, p. 4).

Una actividad profesional tan heterogénea en su definición, orientación y concreción, con competencias personales y técnicas tan específicas, no facilita un amplio acuerdo en torno a cómo se han de articular los procesos de formación que faculten para su ejercicio (Rodríguez-Picavea Matilla, 2007: 118-119). No faltan quienes, por un lado, demandan la puesta en marcha de una rama de formación profesional (López-Pérez, 2012: 119) y, en el lado opuesto, tampoco son escasos los que abogan por una formación "a la carta". Los diferentes implicados e implicadas en el proyecto piloto objeto de estudio no descartan la validez e importancia de una formación básica reglada que establezca una base fundamentalmente ética, pero la capacitación en tareas, habilidades y destrezas debe ser individualizada, adecuada a las características del asistente personal y, sobre todo, determinada por la persona beneficiaria:

"La asistente personal ha pasado por una formación de 40 horas, con personal de la casa, personas del Foro de Vida Independiente y, además, ella complementa su formación in situ. Creemos que hay que tener una visión global de lo que es el movimiento de vida independiente, de la asistencia personal y de las características de las personas con dependencia y con necesidades de apoyo, pero creemos que la familia y el usuario tienen que rematar esa formación" (Entr. 0102. Coordinadora del SAP, p. 4).

La mayoría de las entidades participantes en el proyecto piloto reclutaron a los asistentes personales entre personas integrantes o cercanas a la propia organización, lo que hizo más fácil una formación genérica sobre 
el SAP. Se incluyeron aspectos básicos, instrumentales, éticos y de filosofía del movimiento de vida independiente, complementados con orientaciones específicas en virtud de la visión organizativa del servicio y/o de las características de la persona beneficiaria.

\section{Valoración del servicio de asistencia personal: alcance y dificultades}

La valoración general del SAP que hemos podido recoger a través de la información que nos ha aportado el trabajo de campo tiene una orientación muy positiva, reflejando beneficios percibidos por las personas implicadas que habitualmente no tienen espacio en los estudios sobre el retorno social de este servicio (Huete García y Quezada García, 2014). Las voces y las opiniones de estos agentes son plurales, pero... ¿Reflejan coincidencias en el reconocimiento de las oportunidades que el servicio introduce en la vida de las personas que lo disfrutan?, ¿expresan matices de distinto signo?, ¿qué obstáculos aparecen en su implementación? Abordamos brevemente estos interrogantes siguiendo cuatro líneas argumentales: significado del servicio, impacto apreciado en personas, naturaleza de la ayuda que presta y dificultades en su implantación.

En primer lugar, el SAP, como ningún otro recurso o servicio, representa el cambio conceptual experimentado en torno a la discapacidad intelectual y enfermedad mental grave. Implica un replanteamiento de las formas de atención y de asistencia que tradicionalmente han recibido las personas y sus familiares. De manera manifiesta, contribuye a la mejora de la autonomía y calidad de vida de las personas, destacando su plasticidad y adaptación y sirviendo de nexo de los esfuerzos de servicios de distinta naturaleza por la inclusión social de las personas con enfermedad mental grave y/o discapacidad intelectual:

"Puede beneficiarse cualquier persona, no veo un perfil determinado: hay gente que necesita más tiempo y gente con menos o en periodos de crisis. Yo creo que depende más de los tiempos, de los apoyos, que del tipo de persona (...). Una de las funciones (del SAP), desde mi punto de vista, es hacer de nexo de unión entre diferentes instituciones y adaptarles a las actividades que quieren" (GD4. Asistentes personales, p. 10).

El apoyo prestado por los asistentes personales es muy estimado por las personas atendidas y por sus familiares. Las primeras, con más o menos expresividad e intensidad, insisten en la mejora que ha experimentado sus vidas con el SAP: repercute positivamente en su estado de ánimo, en su autoestima, en sus emociones y sentimientos, les ayuda a descubrir y recuperar actitudes y capacidades ocultas o no percibidas anteriormente. Este servicio también contribuye a que las personas se reconozcan y acepten, a no negar ni ocultar su enfermedad mental o su discapacidad intelectual, a crecer personalmente, a generar y mantener redes personales que difícilmente construirían solo desde el apoyo familiar (en coincidencia con los resultados de la investigación con adolescentes con discapacidad intelectual realizada por Hultman et al., 2015).

El asistente personal les orienta en sus decisiones, les ofrece apoyo y asesoramiento, estimula su participación social y favorece su sociabilidad. Además, les facilita el contacto con el mundo exterior, el acceso al estudio o a un trabajo remunerado, la participación en actividades de ocio. También les anima a salir de su aislamiento incorporándose a la sociedad superando recelos y temores sociales y haciendo frente a resistencias psicológicas muy vinculadas a la autopercepción de su enfermedad y/o discapacidad: 


\begin{abstract}
"Yo antes pensaba que no tenía sentimientos, que era... ¿cómo se llama esto? Una persona que no sabe querer. Hasta ahora yo no era consciente de que yo era una enferma mental (...). Yo no soy una persona de salir, soy más bien una persona de auto-encerrarme en mí misma... Pues solo el mero hecho de que va a venir ella y por no dejarle mal o porque no me eche la bronca, pues me obliga a ir. Me dice: 'mira vamos a salir, vamos a dar una vuelta...' Te obliga a tener un comportamiento social con las personas, que eso es muy importante, poder hablar con personas" (GD3. Beneficiarios/as y familiares del SAP, p. 14).
\end{abstract}

Pero los beneficios de este servicio no se limitan a las personas destinatarias directas; sino también a las familias, llamadas a tener un papel relevante en las medidas para la autonomía de las personas con discapacidad. Tal y como han apuntado Fyffe et al. (2015), se ven directamente beneficiadas por el SAP porque este contribuye, en el marco de una organización con equipos de trabajo multiprofesionales, a una mejor orientación y apoyo a las familias y también, a una cierta descarga y liberación en su labor de cuidado:

"Lo que estamos viendo es que las familias son muchas veces dejadas solas con las problemáticas que tienen los hijos y no siempre saben cómo moverse. Aunque hay centro de salud mental y apoyos, se sienten un poco abandonadas" (GD4. Asistentes personales, p. 12).

Es fácil justificar, desde esta constatación, que el SAP tiene una clara vocación de servicio a la estrategia de inclusión de la persona en su medio social, vinculando a las personas que apoyan con los recursos de su comunidad:

"La figura del asistente personal es que realmente yo creo que es comunitaria por necesidad. Lo comunitario es lo que te permite ser parte activa, cuando tú no vas como colectivo, cuando vas como individuo a participar de la vida ciudadana" (GD2. Gerentes de entidades prestadoras del SAP, p. 18).

Como ya dijimos anteriormente, el servicio persigue incidir en las estructuras, en los marcos y en los entornos sociales que limitan su incorporación y reconocimiento. Los resultados obtenidos y la percepción de los mismos, en esta línea, son muy favorables: la personas que cuentan con este servicio profesional se integran en actividades comunitarias, eligen cómo y dónde desean vivir, pueden permanecer en el lugar en el que residen si lo desean, mantienen sus vínculos, continúan actividades o inician otras que antes tenían vedadas.

Esta unanimidad valorativa también se observa a la hora de evaluar las dificultades que implica la implantación del SAP, si bien estas varían dependiendo de los agentes que realizan la reflexión. Las coordinadoras del SAP y los gestores de las entidades que lo prestan, por ejemplo, consideran que su extensión queda comprometida por el desconocimiento de la naturaleza de la asistencia personal por parte de los servicios sociales básicos (puerta de entrada a los servicios sociales especializados) y las demoras en la tramitación de las ayudas y ciertos problemas de compatibilidad entre prestaciones. Identifican, también, en el seno de las propias entidades, dificultades derivadas de los intensos cambios culturales, organizativos y de gestión económica a los que aboca el SAP cuando este se considera una apuesta institucional a las entidades cogestoras:

"Es una apuesta estratégica clarísima, o sea, de hecho, a veces da un poco de vértigo el decir: ¿hacia dónde vamos? Vamos perdidas, lo asumimos con nuestros números rojos (...). Hay casos urgentes pero que dices: es que esto lo tengo que hacer" (GD2. Gerentes de entidades prestadoras del SAP, p. 14). 
En línea con lo observado en otros trabajos que analizan la implementación del SAP para personas con discapacidad intelectual (Askheim, 2003; Castillo, 2014), entre las personas beneficiarias y sus familiares, sobresalen preocupaciones que tienen un triple origen. Algunas derivan de la naturaleza del servicio, ya que el empoderamiento del beneficiario/a cuestiona patrones de conducta híper protectora y paternalista muy asentados. Otras tienen que ver con su implementación, puesto que no son fáciles los procesos de negociación para la toma de decisiones, los familiares asignan al asistente personal un rol de cuidador/a, policía o padre/amigo que no le corresponde, y otras conectan con su financiación, ya que los costes económicos que implica disponer de un asistente personal no siempre quedan cubiertos por la prestación pública o no lo hacen integramente:

"Yo, por ejemplo, estoy haciendo esto porque económicamente me lo puedo permitir ahora, si yo ahora mismo no hubiera pensado en que esto pudiera ocurrir y no hubiera preparado una dotación económica para esto... No, muchas familias no pueden hacerlo" (Entr. 0105. Familiar de beneficiario/a del SAP p. 8).

Los asistentes personales manifiestan una gran satisfacción con el trabajo que realizan y el crecimiento profesional y personal que han vivido en el ejercicio de su rol, al igual que se recoge en otros trabajos empíricos (Schelly, 2008). No obstante, sus reflexiones contribuyen a completar el mapa de elementos que, desde su punto de vista, dificultan la implantación del SAP. Ellos ponen el foco en su ejercicio profesional y en las condiciones laborales en que este se produce: su dedicación y la dificultad que entraña su trabajo no tienen, a su juicio, un adecuado reconocimiento en la retribución; el estrés que implica la atención a personas con discapacidad intelectual y enfermedad mental grave es mayor que en el caso de la discapacidad física (Scott y McClure Cassie, 2007); la disponibilidad y flexibilidad para acomodarse y adaptarse a los horarios que les marcan las personas atendidas pueden generar problemas de conciliación entre su vida personal y laboral, y la ausencia de una categoría laboral específica conlleva su asimilación a la figura de cuidador con sus condiciones laborales y económicas.

"Desde el punto de vista del trabajo estás siempre disponible, no es como un trabajo cualquiera que va de esta hora a tal hora, y luego tienes tu vida. El horario... sí que es complicado, yo lo noto en la vida de pareja (...). No me veo dentro de diez años aquí por las condiciones de trabajo. Ahora genial, ¿qué pasará cuando pasen unos años y nosotras queramos tener una familia y organizar tu vida un poco?” (GD4. Asistentes personales, pp. 22 y 24).

Estas limitaciones revelan el carácter incipiente del servicio y alertan sobre la necesidad de afrontar sus potencialidades y desafíos.

\section{Conclusiones}

Las evidencias procedentes de la aplicación de las distintas estrategias de investigación articuladas en este estudio permiten afirmar que el SAP representa, como ningún otro servicio, una nueva manera de ayudar a las personas con discapacidad intelectual y enfermedad mental grave. Este servicio supone una auténtica subversión de la forma tradicional de entender y hacer efectivo el proceso de ayuda a este colectivo en la 
medida en que, superando planteamientos basados en lógicas clínico-rehabilitadoras o en el apoyo familiar, se pasa de un modelo de atención centrado en la persona a otro modelo planificado por la persona. El eje central y el protagonismo ya no descansa en el técnico ni en el cuidador, sino que lo asume la persona con discapacidad.

Las mejoras que introduce el nuevo servicio son amplias y diversas, con un alcance y una proyección no solo individual, sino también social, cultural y económico (ver, por ejemplo, láñez-Domínguez et al., 2018). Al tiempo que incrementa el bienestar de las personas con enfermedad mental y discapacidad intelectual y el de sus familias, impulsa su reconocimiento y aceptación social, favoreciendo el cambio de los patrones culturales dominantes en nuestra sociedad, sobre la discapacidad y la enfermedad mental.

A pesar de ser un servicio contemplado en la financiación del Sistema para la Autonomía y Atención a la Dependencia, su desarrollo es aún escaso -en abril de 2019 se financiaron 6.672 prestaciones de asistencia personal, lo que supone el $0,62 \%$ del total de prestaciones financiadas ${ }^{3}$. Las razones de unos datos tan sorprendentes descansan en la complejidad de su implementación: no resulta fácil romper con inercias personales, familiares, profesionales, culturales, organizativas... No obstante, este estudio ha evidenciado dos hechos muy significativos que alientan su extensión. De un lado, este servicio, por sus cualidades esenciales, es diferente a otros servicios y prestaciones con los que, sin embargo, no se observan líneas de fricción sino ámbitos y posibilidades de complementariedad. De otro, es considerado por todas las personas implicadas como un recurso extraordinario que contribuye como ningún otro a facilitar la autonomía de las personas con discapacidad intelectual y enfermedad mental grave.

Su promoción puede suponer una extraordinaria oportunidad de mejora en las atenciones a estos colectivos, así como una importante fuente de empleo. El progreso en su extensión y consolidación dependerá, no obstante, de la capacidad de articular y conciliar coherentemente los distintos asuntos claves o dimensiones que lo conforman: la dimensión axiológica o de valores contenidos en la fórmula de vida independiente; la dimensión metodológica-estratégica, que representa la libertad del "consumidor/a" con capacidad de elegir los distintos componentes de las atenciones (servicios) requeridos (contenido, lugar, momento, estilo...); la dimensión laboral, en la medida que las relaciones entre el asistente personal y la persona ayudada están sometidas a regulaciones relativas al derecho del trabajo (contrato, servicios, tiempo, disponibilidad, obligaciones, derechos, retribuciones...); la dimensión profesional, puesto que se trata de un servicio personal que requiere de unas competencias (cualificación) ajustadas al tipo de demandas solicitadas por el cliente y contratante; y, por último, la dimensión deontológica, que alude a las normas éticas referidas a los servicios y que deben asegurar que el objeto principal (la vida independiente) se alcance.

Los retos no son sencillos. La investigación que hemos realizado ha detectado algunas cuestiones en las que se ha de avanzar para facilitar que este servicio pueda extenderse y consolidarse como herramienta para la autodeterminación e inclusión comunitaria de personas con discapacidad intelectual y/o enfermedad mental grave.

De un lado, las organizaciones prestadoras del servicio aportan a las personas con discapacidad intelectual y a sus familias elementos de gran valor (confianza, seguridad, formación, seguimiento, apoyo en gestio-

3. IMSERSO - SISAAD (Sistema de Información del Sistema para la Autonomía y Atención a la Dependencia), Portal de la Dependencia. Datos a 30 de abril de 2019: http://www.dependencia.imserso.es/dependencia_01/saad/sisaad/estadisticas_sisaad/index.htm, acceso 25 de mayo de 2019). 
nes...) y hacen posible que el SAP se convierta en una eficaz estrategia de apoyo para su inserción en la comunidad. Deben, sin embargo, dar cabida a un modelo de atención que implica innovaciones culturales, laborales, técnicas, organizacionales y económicas de gran alcance. Ese proceso, por ejemplo, implica asumir los principios del servicio, reconocer su singularidad y especificidad, establecer formas de articulación y conexión con otros servicios y, sin duda, afrontar los costes económicos y organizativos que conlleva su gestión y prestación.

De otro lado, el servicio demanda profesionales cualificados. Los asistentes personales realizan tareas muy variadas que exigen una adecuada preparación sobre la que no existe acuerdo institucional y que es preciso establecer. Las posturas varían entre propuestas maximalistas (formación reglada bien estructurada y definida) y fórmulas que reducen la preparación a las tareas que se han de acometer y a las características de la persona beneficiaria. Entre los participantes en el proyecto piloto una buena parte apuesta por una visión conciliadora que reconoce la importancia de una formación básica (fundamentalmente ética) y el carácter imprescindible de una preparación ad hoc en las tareas, habilidades y destrezas que recomienden las capacidades de la persona con discapacidad.

Por último, como se ha documentado también en otros entornos (Morris, 2004), el acceso al SAP conlleva desafíos relativos a su concepción, financiación y difusión. El riesgo de que puedan darse diferentes interpretaciones en la comprensión y aplicación del servicio exige una regulación que, sin constreñir en exceso su prestación, impida abusos y deformaciones. Además, los costes de su gestión recomiendan revisar las fórmulas de financiación de manera que se garantice el acceso al servicio a todas las personas que lo necesitan y demandan. Tampoco se pueden olvidar las resistencias y desconfianzas que la novedad del servicio y el carácter radical de su planteamiento pueden generar entre personas con discapacidad intelectual y familiares, y la dispar extensión de la prestación económica de asistencia personal entre comunidades autónomas, que obliga a una evaluación de las políticas públicas de fomento y apoyo a la asistencia personal...

De cómo se afronten estos retos dependerá que las personas con discapacidad intelectual y/o enfermedad mental grave puedan disfrutar de este tan eficaz y prometedor servicio para lograr una verdadera vida independiente. 
Referencias bibliográficas

Alonso, L. E. (2003): La mirada cualitativa en sociología. Madrid: Fundamentos.

Asís, R. y Barranco, M. C. (2010): El impacto de la Convención Internacional sobre los Derechos de las Personas con Discapacidad en la Ley 39/2006, de 14 de diciembre. Madrid: Cinca-CERMI.

Askheim, O. P. (2003): "Personal Assistance for People with Intellectual Impairments: Experiences and dilemas". Disability \& Society, 18 (3): 325-339.

Axelsson, A. K et al. (2014): "Strategies that facilitate participation in family activities of children and adolescents with profound intellectual and multiple disabilities: parents' and personal assistants' experiences". Disability and Rehabilitation, 36 (25): 2169-2177.

Barrón, A. (1996): Apoyo social. Aspectos teóricos y aplicaciones. Madrid: Siglo XXI.

Brisenden, S. (1986): "Independent Living and the Medical Model of Disability". Disability, Handicap \& Society, 1 (2): 173-178.

Boyatsis, R. (1998): Transforming Qualitative Information: Thematic Analysis and Code Development. London: Sage.

Castillo, T. (2014): "La persona protagonista de su vida independiente. Un modelo de escucha de profesionales y familia”. Educació Social. Revista d'Intervenció Socioeducativa, 58: 29-44.

COCARMI (2016): El COCARMI defiende el uso del término 'personas con discapacidad' en lugar de "personas con diversidad funcional": No nos cambies de nombre, ayúdanos a cambiar la realidad" (en línea). <http://www. cocarmi.cat/sites/default/files/np_no_ens_canviis_el_nom_v1.2_cast.pdf>, acceso 18 de diciembre de 2018.

European Network on Independent Living (2014): Informe sobre los Servicios de Asistencia Personal en Europa (en línea). <http://www.enil.eu/wp-content/uploads/2012/06/European-Survey-on-Personal-Assistance-Final. pdf>, acceso 18 de diciembre de 2018.

Fyffe, C. et al. (2015): "Improving Policy and Practice: Adults with Intellectual Disabilities and Their Families". Journal Research and Practice in Intellectual and Developmental Disabilities, 2 (1): 73-78.

García Alonso, J. V. (coord.) (2003): Movimiento de Vida Independiente. Experiencias internacionales. Madrid: Fundación Luis Vives.

Giménez Bertomeu, V. (2014). "Cuestiones éticas en la investigación en Trabajo Social y estrategias para una investigación éticamente responsable”. Revista Internacional de Trabajo Social y Bienestar-AZARBE, 3: 187-195.

González Gago, E. (2010): La coordinación, el liderazgo y el trabajo en red para la inclusión activa en el ámbito local. Madrid: Fundación Luis Vives.

Huete García, A. y Quezada García, M. Y. (2014): "Análisis de Retorno Social de la Inversión en dos sistemas de apoyo a personas con gran discapacidad: asistencia personal y servicio residencial. Un estudio de caso". Revista Española de Discapacidad, 2 (1): 51-69.

láñez-Domínguez, A. y Lobato Galindo, M. (2006): "Reflexiones sobre cómo abordar la (in)dependencia de las personas con diversidad funcional”. Acciones e investigaciones sociales, número extra 1: 260. 
láñez-Domínguez, A. et al. (2018): "Impacto económico y social de la asistencia personal a través de la metodología del Retorno Social de la Inversión”. Revista Española de Discapacidad, 6 (II): 81-102.

Hughes, B. y Paterson, K. (1997): "The Social Model of Disability and the Disappearing Body: Towards a sociology of impairment”. Disability \& Society, 12 (3): 325-340.

Hultman, L. et al. (2015): "Assisted normality - a grounded theory of adolescent's experiences of living with personal assistance". Disability and Rehabilitation, 38 (11): 1053-1062.

López-Pérez, M. (2012): "Prestación económica de asistencia personal: asignatura pendiente de la Ley 39/2006, de 14 de diciembre". Portularia, XII, número extra: 111-120.

López-Pérez, M. y Ruiz Seisdedos, S. (2013): “Asistencia Personal: herramienta para una vida independiente. Situación actual”. Aposta, Revista de Ciencias Sociales, 59.

Martínez, K. (2003): "El Movimiento de Vida Independiente en Estados Unidos", en García Alonso, J. V. (coord.): Movimiento de Vida Independiente. Experiencias internacionales. Madrid: Fundación Luis Vives.

Morris, J. (2004): "Independent living and community care: a disempowering framework". Disability \& Society, 19 (5): 427-442.

Moscoso, M. (2006): "Lo que no somos: una breve reflexión a propósito de la discapacidad". La ortiga: revista cuatrimestral de pensamiento y arte, 68-70: 73-89.

Oliver, M. (1983): Social Work with Disabled People. Basingstoke: Macmillan.

Ortega Alonso, E. (coord.) (2015): Situación de la Asistencia Personal en España. Madrid: PREDIF.

Palacios, A. y Bariffi, F. (2007): La discapacidad como una cuestión de derechos humanos. Madrid: Cinca-CERMI.

Palacios, A. y Romañach, J. (2006): El modelo de la diversidad. La Bioética y los Derechos Humanos como herramientas para alcanzar la plena dignidad en la diversidad funcional. Madrid: Diversitas Ediciones.

Palacios Rizzo, A. (2008): El modelo social de discapacidad: orígenes, caracterización y plasmación en la Convención Internacional sobre los Derechos de las Personas con Discapacidad. Madrid: CINCA.

Planas García de Dios, M. J. (2013): "El asistente personal para las personas con diversidad funcional: una herramienta para el cumplimiento de derechos". Revista Trabajo Social Hoy, 68: 31-54.

Power, A. (2013): "Understanding the complex negotiations in fulfilling the right to independent living for disabled people". Disability \& Society, 28 (2): 204-217.

Rodríguez Castedo, Á. (dir.) (2004): Libro Blanco de atención a las personas con situación de dependencia en España. Madrid: Ministerio de Trabajo y Asuntos Sociales.

Rodríguez-Picavea Matilla, A. (2007): "Reflexiones en torno a la figura del asistente personal para la vida independiente y la promoción de la autonomía de las personas con diversidad funcional (discapacidad)". Zerbitzuan, 41: 115-127.

Rodríguez-Picavea Matilla, A. (2010): “Vida independiente, dignidad y derechos”, en González García, M.L. et al. (comp.): Actas del IX Congreso de Estudiantes de Terapia Ocupacional.

Román, B. (2010): "La ética en los servicios de atención a las personas con discapacidad intelectual severa. ¿Por qué?”, en Fundació Víctor Grífols i Lucas (coord.): La ética en los servicios de atención a las personas con discapacidad intelectual severa. Barcelona: Fundació Víctor Grífols i Lucas. 
Romañach, J. y Lobato, M. I. (2005): Diversidad funcional, nuevo término para la lucha por la dignidad en la diversidad del ser humano. Madrid: Foro de Vida Independiente.

Rueda, M. (2013): Análisis comparativo de las iniciativas de vida independiente en España. Madrid: Foro de Vida Independiente.

Ruiz Olabuénaga, J. I. (2012): Metodología de la investigación cualitativa. Bilbao: Deusto.

Schelly, D. (2008): "Problems associated with choice and quality of life for an individual with intellectual disability: a personal assistant's reflexive ethnography”. Disability \& Society, 23 (7): 719-732.

Scott, K. R. y McClure Cassie, K. (2007): "Stress and Strain Among Personal Care Assistants at an Assisted Living Facility”. Journal of Evidence Based Social Work, 4 (1): 47-59.

Suárez-Ortega, M. (2005): El grupo de discusión. Una herramienta para la investigación cualitativa. Barcelona: Laertes.

Ubieto Pardo, J. R. (2009): El trabajo en red: usos posibles en educación, salud mental y servicios sociales. Barcelona: Gedisa.

Vallés, M. S. (2002): Entrevistas cualitativas. Madrid: Centro de Investigaciones Sociológicas.

Vázquez Ferreira, M. A. (2008): “Una aproximación sociológica a la discapacidad desde el modelo social: apuntes caracterológicos”. Revista Española de Investigaciones Sociológicas, 124, 141-174.

Villa Fernández, N. (2012): “¿Realidad o deseo para las personas con diversidad intelectual?”, en Hidalgo Lavié, A. (coord.): Trabajo Social en defensa de la asistencia personal. Reflexiones y sugerencias. Madrid: UNED Consejo General del Trabajo Social - Netbiblo. 